\title{
Profissional da informação: análise da inserção no mercado de trabalho brasileiro*
}

Mônica de Fátima Loureiro

\author{
Bacharel em Biblioteconomia; Mestre em Ciência \\ da Informação, Pontifícia Universidade Católica \\ de Campinas (PUC-Campinas); Doutoranda em \\ Ciência da Informação e Documentação, \\ Universidade de São Paulo.
}

Paulo de Martino Jannuzzi

\begin{abstract}
Doutor em Demografia; Professor do Programa de Mestrado em Estudos Populacionais e Pesquisas Sociais. Escola Nacional de Ciências Estatísticas do IBGE. Rio de Janeiro, RJ, Brasil.
\end{abstract}

Procurando contribuir para a discussão acerca da inserção do profissional da informação no mercado de trabalho no Brasil, discussão essa muito marcada por estudos de natureza ensaística, estudos de caso particulares e pesquisas empíricas de pequeno alcance e representatividade, o presente estudo tem como objetivo trazer evidências empíricas mais gerais e atuais a respeito da inserção destes profissionais no mercado de trabalho, na forma permitida pelo Censo Demográfico 2000. Mais especificamente, a pesquisa tem como objetivo o dimensionamento e caracterização do contingente de profissionais em atividades de informação que atuavam no mercado de trabalho brasileiro no ano 2000, segundo as categorias da Classificação Brasileira de Ocupações, a saber: profissionais da informação; arquivistas e museólogos; técnicos em biblioteconomia; técnicos em museologia e afins; auxiliares de serviços de documentação, informação e pesquisa. Apresenta-se o contingente de profissionais no país e; então, mostra-se a distribuição desses profissionais nas diversas regiões. Aborda-se ainda uma caracterização de cada grupo ocupacional, através de indicadores de escolaridade, posição na ocupação e o rendimento médio. Mostra-se que o contingente de profissionais do grupo é de $0,1 \%$, em relação ao total da população ocupada no país, com

\footnotetext{
* Trabalho desenvolvido a partir dos resultados da dissertação de mestrado intitulada: 0 bibliotecário como profissional da informação: análise da inserção no mercado de trabalho brasileiro segundo o Censo Demográfico de 2000.
} 
concentração maior nos estados do Sul e Sudeste. Dentre as categorias analisadas os Profissionais da Informação apresentam melhor inserção ocupacional e rendimentos, ainda que em relação aos demais profissionais das Ciências e Artes a situação não seja das mais virtuosas, ao contrário do que poderia intuir pela bibliografia na área.

Palavras-chave: profissional da informação; bibliotecário; mercado de trabalho.

\section{Information professional: analysis of the insertion in the brazilian labour market}

The discussion on the insertion of the information professional in the labor market in Brazil is marked by studies with testing? nature, particular case studies and empirical inquiries of small extent and representativeness. In an attempt to contribute with this discussion, the present study had as the main objective to bring about more general and current empirical evidences about the insertion of these professionals in the labor market, in the form allowed by the Demographic Census 2000. More specifically, the inquiry had as the objective to investigate the dimension and characterization of the professional contingent in information activities acting in the Brazilian labor market in the year 2000, according to the categories of the Brazilian Classification of Occupations, as follows: professionals of the information; archivists and museologists; librarianship technicians; museum technicians and similar; documentation, information and inquiry services assistants. The contingent of professionals and their distribution in the regions of the country are shown. A characterization of each occupational group is also shown, regarding school level, position in the occupation and average income indicators. The inquiry reveals that the professionals contingent of the group is $0.1 \%$ in relation to the country total productive population, with higher concentration in the Southeastern and Southern states. Different from expected from the literature, among the categories analyzed, Information Professionals have better occupational insertion and better incomes in relation to 
professionals of the Sciences and Arts, although the situation of the latter is not very good.

Keywords: Information professional; Librarian; labour market.

\author{
Recebido em 13.11.2006 Aceito em 02.03.2007
}

\title{
Introdução
}

A informação sempre teve grande importância na vida das sociedades, em todos os tempos; porém, atualmente, é reconhecida como insumo básico, passando a ser considerada, em alguns casos, como um ativo, um bem simbólico (BORGES, 2004).

O desenvolvimento das tecnologias de informação e comunicação TIC-, cujo ícone é a internet, está alterando significativamente o modo de vida da população que tem acesso às novidades que essas tecnologias estão implementando. Nesse sentido, verifica-se a ocorrência cada vez mais freqüente de programas de diversos países preparando-se para integrar esse novo ambiente. Um exemplo, no Brasil, é o Livro Verde (TAKAHASHI, 2000), documento que coloca os parâmetros a serem adotados na política brasileira, para diversos setores, visando ao seu ingresso na chamada sociedade da informação (SI), uma iniciativa do Ministério de Ciência e Tecnologia (MCT).

Castells (2002), comentando os reflexos que os processos de transição histórica têm na estrutura ocupacional, isto é, na composição de categorias profissionais e do emprego, entende que o período denominado Era da Informação e do Conhecimento é marcado basicamente pelo processamento da informação, culminando na geração de conhecimentos que se constituem em fontes de produtividade e de crescimento de todas as esferas da atividade econômica.

Comparando a sociedade industrial e a informacional, Castells (2002) ressalta que, como tendência, pode-se considerar que na década de 1990, a maioria da população dos países do G-7 esteve empregada no setor de serviços, mais concentrada, principalmente, nos Estados Unidos e Canadá. Pelo próprio nome adotado para o período atual, Era da Informação e do Conhecimento, é de se esperar que, na nova economia, profissões ligadas aos conteúdos informacionais e ao conhecimento estejam mais bem inseridas do que outras no mercado de trabalho.

Assim, Castells (2002) afirma que cargos como os de administradores, profissionais especializados e técnicos, considerados ricos em atividades de informação, representam o cerne da nova estrutura ocupacional. Entretanto, demonstra também que houve crescimento das profissões em serviços considerados simples e não-qualificados, apontando para uma estrutura social polarizada nesses dois extremos.

Segundo Schwartz (2000), é preciso que os trabalhadores estejam atentos às alterações da economia, preparando-se para mudar a própria 
qualificação profissional, de modo a acompanhar as tendências de mudanças. O autor ainda comenta que "é o trabalhador que precisa se adaptar com rapidez ao mercado, em vez de ficar esperando que surjam, vindas do próprio mercado, as oportunidades que correspondam ao seu perfil atual" (SCHWARTZ, 2000, p. 23).

A nova economia, de acordo com Takahashi (2000), oriunda da difusão das TIC, está ampliando negócios e mercados, além de modernizar e revitalizar segmentos maduros e tradicionais. Mas o autor destaca que empresas e trabalhadores têm como desafio "adquirir a competência necessária para transformar informação em um recurso econômico estratégico, ou seja, o conhecimento" (TAKAHASHI, 2000, p. 17 , grifo do autor).

Porat, citado por Castells (2002, p. 69), entende que

o que caracteriza a atual revolução tecnológica não é a centralidade de conhecimentos e informação, mas a aplicação desses conhecimentos e dessa informação para a geração de conhecimentos e de dispositivos de processamento/ comunicação da informação, em um ciclo de realimentação cumulativo entre a inovação e seu uso.

A economia que surgiu nesse novo contexto, para Schwartz (2000, p. 11), funciona com base em redes de conhecimento. Nessa medida, "transformar-se num elo de uma cadeia de transmissão de conhecimento é a melhor forma de ficar próximo a um bom emprego". Em relação ao perfil do profissional nesse novo ambiente, Schwartz (2000) enfatiza que, diferentemente do profissional generalista que o mercado de trabalho exigia há dez anos, nos dias atuais a ênfase recai sobre os especialistas em generalidades - aqueles que sabem muito sobre várias coisas, ou, melhor dizendo, indivíduos com múltiplas habilidades. "Não é o fim da 'função', mas a valorização do profissional 'multifuncional', capaz de exercer várias funções" ou, apoiando-se em outro conceito, o "job rotation (rodízio de tarefas), que submete o profissional a várias tarefas ou jobs" (SCHWARTZ, 2000, p. 49-50).

Apesar das grandes alterações no campo do trabalho proporcionadas, basicamente, pelo desenvolvimento das TIC e pelo processo de globalização, determinadas áreas tiveram, nesse período, um grande avanço, principalmente as ligadas às TIC. Takahashi (2000, p. 21), destaca que os perfis profissionais de maior sucesso, os mais disputados no mercado de trabalho, são: "programadores, web-designers, administradores de redes, jornalistas e outros profissionais que lidam com conteúdos na web, especialistas em marketing e gerentes de Internet".

De acordo com Miranda (2000), o ingresso na SI relaciona-se diretamente com as novas tecnologias, com a identidade cultural e com conteúdos. Nessa abordagem, vale explicitar mais detalhadamente a questão dos conteúdos, uma vez que estão diretamente relacionados com 
o trabalho dos profissionais da informação (PI). Como definição de conteúdos, termo que o autor utiliza de forma genérica, resume-se "tudo o que é operado na internet" (MIRANDA, 2000, p. 81). Miranda (2000, p. 81), entende que é mediante a operação das redes de conteúdos, de forma geral, que a sociedade brasileira pode se conduzir para a SI, sendo os conteúdos, portanto, "o meio e o fim da gestão da informação, do conhecimento e do aprendizado na sociedade da informação". Nesse sentido destaca-se a importância do

processo de seleção de conteúdos e dos níveis de qualidade relativa - no sentido interpessoal - que deverá ser objeto de análise e controle por parte dos sistemas intermediários de informação, mediante instrumentos adequados nas etapas de formação de estoques, processamento técnico e disseminação. Da ação normalizadora e do tratamento parametrizado dos conteúdos, vai depender sua melhor difusão e uso pela sociedade (MIRANDA, 2000, p. 81, grifo nosso )

As colocações de Miranda (2000) permitem inferir que, no atual momento social, fica mais reconhecida a importância dos profissionais ligados à organização e difusão de informações. Nesse sentido, presumese que os profissionais que lidam com a informação, também ligados ao trabalho de organização e disseminação de conteúdos, devem ter uma melhor inserção no mercado de trabalho, nos dias atuais.

De fato, Jannuzzi e Mattos (2001, p. 128), estudando o comportamento do mercado de trabalho dos profissionais que trabalhavam com o tratamento, análise e difusão da informação no Brasil, nas décadas de 1980 e 1990, concluíram que houve dificuldades na inserção deles no mercado de trabalho, devido a vicissitudes da conjuntura econômica. No entanto, mesmo com os problemas detectados, a inserção dessa categoria ficou, em relação a outras, acima da média nacional.

Procurando contribuir para essa discussão, muito marcada por estudos de natureza ensaística, estudos de caso particulares e pesquisas empíricas de pequeno alcance e representatividade, o presente estudo tem como objetivo trazer evidências empíricas mais gerais e atuais a respeito da inserção destes profissionais no mercado de trabalho, na forma permitida pelo Censo Demográfico 2000. Mais especificamente, a pesquisa tem como objetivo o dimensionamento do contingente de profissionais em atividades de informação que atuavam no mercado de trabalho brasileiro no ano 2000, segundo as categorias da Classificação Brasileira de Ocupações, a saber: profissionais da informação (código CBO 2612); e arquivistas e museólogos (código 2613), de nível superior (Quadro 1); técnicos em biblioteconomia (código 3711); técnicos em museologia e afins (código 3712), de nível médio; e pelos auxiliares de serviços de documentação, informação e pesquisa (código 4151), de nível administrativo (QUAD. 2). 
Parte-se da hipótese de que, no Brasil, os profissionais que trabalham com a informação estariam aumentando em taxas mais elevadas, continuariam melhor inseridos no mercado de trabalho e presentes com maior intensidade nos estados mais desenvolvidos - São Paulo, Rio de Janeiro, Rio Grande do Sul.

Inicialmente descreve-se as categorias que compuseram o grupo objeto de estudo desta pesquisa: "pessoal ocupado em atividades de informação". Em seguida apresenta-se o contingente de profissionais no país e; então, mostra-se a distribuição desses profissionais nas diversas regiões. Aborda-se ainda uma caracterização de cada grupo ocupacional, através de indicadores de escolaridade, posição na ocupação e o rendimento médio. Finalmente são apresentadas algumas conclusões em relação aos resultados obtidos.

\section{As categorias de pessoal ocupado em atividades de informação}

Entende-se que não existe consenso em relação ao conceito de profissional da informação, mas uma diversidade de definições sobre os profissionais que compõem a categoria dos PI. Como a intenção desta pesquisa foi investigar a inserção dos profissionais que lidam com a informação no mercado de trabalho brasileiro, em uma perspectiva empírica, foram adotadas as definições propostas pela CBO de 2002 (BRASIL, 2003). Tal escolha se baseou no conceito de Smit (2000) sobre as áreas irmãs: Arquivologia, Biblioteconomia, Documentação e Museologia, apenas incluindo os profissionais de nível médio e administrativo que atuam nessas frentes.

Outro ponto a ser ressaltado é que a própria CBO de 2002 (BRASIL, 2003), para definir suas categorias, pela primeira vez, consultou autoridades reconhecidas de várias instituições do país em cada área de atuação, refletindo, mais ou menos, o desenvolvimento das denominações, principalmente se referindo ao profissional da informação e afins.

Nesse sentido é preciso comentar uma das diferenças entre a CBO de 1994 (BRASIL, c1995) e a CBO de 2002 (BRASIL, 2003), em relação à constituição da família dos profissionais que lidam com a informação. Na CBO de 1994 (BRASIL, c1995) os bibliotecários, arquivologistas e museólogos compunham o grupo de base 1-91 que fazia parte do subgrupo 1-9 "Trabalhadores das Profissões Científicas, Técnicas, Artísticas e Trabalhadores Assemelhados Não-Classificados Sob Outras Epígrafes". Já na CBO de 2002 (BRASIL, 2003) existe a categoria Profissionais da Informação (código 2612), formada pelo bibliotecário, pelo documentalista e pelo analista de informações. Outra categoria é a dos arquivistas e museólogos (código 2613), composta somente pelo arquivista e pelo museólogo. Nota-se aí uma separação entre os profissionais das áreas consideradas irmãs.

Deve ser notada a diferenciação do próprio título do profissional do arquivo, que na CBO de 1994 é arquivologista e na CBO de 2002 é 
arquivista. Outro ponto de mudança entre uma classificação e outra é que na CBO de 1994 (BRASIL, c1995, p. 172) existe um código (1-91.90) para

outros bibliotecários, arquivologistas e museólogos no qual são incluídos os profissionais dessas categorias que não são classificados nas anteriores epígrafes deste grupo de base, por exemplo, os que se especializam na aquisição, avaliação, classificação, compilação e catalogação de documentos sobre assuntos de interesse para organizações comerciais e de outro gênero.

Esse tipo de divisão desapareceu na CBO de 2002.

É preciso justificar a inclusão dos profissionais de nível médio e administrativo no grupo pessoal ocupado em atividades de informação. Apesar de se entender que os profissionais de nível médio e administrativo trabalham com o suporte ao invés de trabalharem com a informação efetivamente, eles estão ligados a atividades de informação. Esta pesquisa pretende investigar, de acordo com a própria denominação do grupo a ser estudado, todo o pessoal que atua em atividades de informação, não se atendo aos PI, nem somente aos profissionais de nível superior como arquivistas, bibliotecários e museólogos.

Diferentemente de Jannuzzi e Mattos (2001), que incluíram na categoria dos profissionais da informação, professores universitários, jornalistas e escritores, entre outros profissionais, o grupo formado para esse estudo, denominado pessoal ocupado em atividades de informação, não incluirá, por exemplo, professores de arquivologia, biblioteconomia ou museologia do ensino superior, pelo fato de o código da família, 2347 ser o mesmo para docentes de outras áreas, como de antropologia, ciência política, comunicação social, direito, filosofia, geografia, história, jornalismo, psicologia, serviço social e sociologia; o que causaria problemas em relação aos dados coletados no Censo Demográfico, que se centra no grande código (de quatro dígitos) da família.

O processamento dos microdados do Censo 2000 teve início em julho de 2004 e, para isso, utilizou-se o software SPSS for Windows, versão 11.0 (STATISTICAL..., 2001). Em primeiro lugar, é preciso destacar alguns pontos a serem considerados, quando da observação dos números apresentados:

1) Pelo fato de se trabalhar com pessoas ocupadas, procedeu-se a um filtro geral, que separou, para processamento, somente os registros de pessoas em que a faixa etária ficasse entre 10 e 65 anos $^{*}$, o que ocasionou, em algumas tabelas, pequenas diferenças amostrais, porém, dentro do limite permitido;

2) Outro fator que interferiu no processamento é que os microdados do Censo possuem uma variável de peso (P001), que foi acionada durante

\footnotetext{
* O corte inicial baixo (10 anos), visa refletir a realidade do mercado de trabalho brasileiro e o corte final (aos 65 anos), foi estabelecido por aposentadoria.
} 
todos os cruzamentos para que as estimativas fossem corretamente calculadas. Também devem ser consideradas situações em que ocorreram problemas na própria coleta do dado pelos entrevistadores do Censo, citando, como exemplo, casos de idade não declarada. Situações como essa fazem com que certos registros não sejam incluídos em nenhuma das faixas estabelecidas para o processamento, trazendo como resultado pequenas diferenças nos totais encontrados, em especial no caso de tabelas cruzadas;

3) O grupo denominado Outros Profissionais das Ciências e das Artes, considerado, para essa pesquisa, grupo comparativo, é formado por profissionais de várias frentes, e inclui os Pesquisadores e Profissionais Policientíficos; Profissionais das Ciências Exatas, Físicas e da Engenharia; Profissionais das Ciências Biológicas, da Saúde e afins; Profissionais do Ensino - e, entre eles, destacam-se os Professores de Arquivologia, Biblioteconomia e Museologia; Profissionais das Ciências Jurídicas; Profissionais das Ciências Sociais e Humanas e Comunicadores, Artistas e Religiosos (BRASIL, 2003). Para o processamento dos microdados da categoria Outros Profissionais das Ciências e das Artes, foram excluídos os grupos dos Profissionais da Informação (Código 2612) e dos Arquivistas e Museólogos (Código 2613), pelo fato de estas categorias já estarem explicitadas e destacadas, sendo parte do objeto de estudo desta pesquisa.

4) Vale observar que a análise da distribuição dos profissionais pelas regiões deve ser feita com cautela, por causa do erro amostral a que certos grupos como o de Técnicos em Museologia e afins, por exemplo, estão sujeitos. 

QUADRO 1 - Pessoal Ocupado em Atividades de Informação de nível
superior segundo a Classificação Brasileira de Ocupações de 2002.

\begin{tabular}{|c|c|c|c|c|}
\hline Código & $\begin{array}{l}\text { Categoria } \\
\text { CBO }\end{array}$ & $\begin{array}{c}\text { Títulos } \\
\text { Ocupacionais }\end{array}$ & Outras denominações & Descrição Sumária \\
\hline \multirow[t]{13}{*}{2612} & \multirow{13}{*}{$\begin{array}{l}\text { Profissionais } \\
\text { da } \\
\text { informação }\end{array}$} & \multirow[t]{6}{*}{ Bibliotecário } & Bibliógrafo & \multirow{13}{*}{ 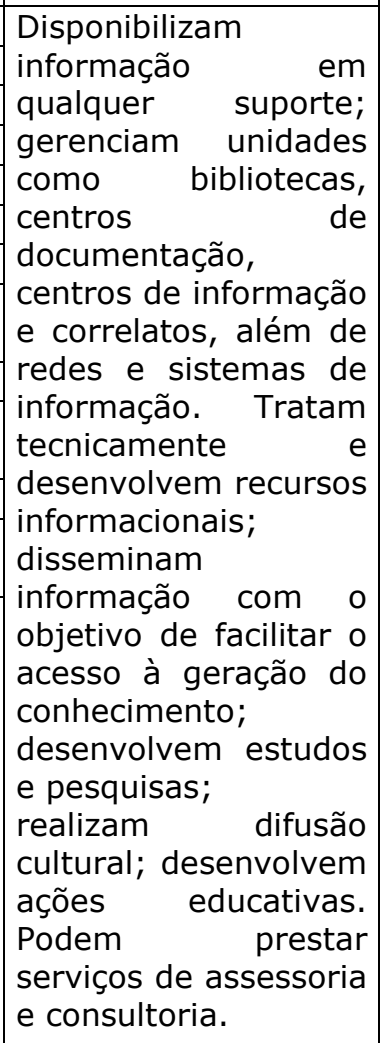 } \\
\hline & & & Biblioteconomista & \\
\hline & & & Cientista da informação & \\
\hline & & & Consultor de informação & \\
\hline & & & Especialista de informação & \\
\hline & & & Gestor de informação & \\
\hline & & \multirow{6}{*}{ Documentalista } & Analista de documentação & \\
\hline & & & $\begin{array}{l}\text { Especialista de } \\
\text { documentação }\end{array}$ & \\
\hline & & & Gerente de documentação & \\
\hline & & & $\begin{array}{l}\begin{array}{l}\text { Supervisor de controle } \\
\text { documental }\end{array} \\
\end{array}$ & \\
\hline & & & Técnico de documentação & \\
\hline & & & $\begin{array}{l}\text { Técnico de suporte em } \\
\text { documentação }\end{array}$ & \\
\hline & & $\begin{array}{l}\text { Analista de } \\
\text { informações } \\
\text { (pesquisador de } \\
\text { informações de } \\
\text { rede) }\end{array}$ & $\begin{array}{l}\text { Pesquisador de informações } \\
\text { de rede }\end{array}$ & \\
\hline \multirow[t]{11}{*}{2613} & \multirow[t]{11}{*}{$\begin{array}{l}\text { Arquivistas e } \\
\text { museólogos }\end{array}$} & \multirow[t]{5}{*}{ Arquivista } & $\begin{array}{l}\text { Administrador de arquivos } \\
\text { Encarregado de servico de }\end{array}$ & \multirow{11}{*}{$\begin{array}{l}\text { Organizam } \\
\text { documentação de } \\
\text { arquivos institucionais } \\
\text { e pessoais, criam } \\
\text { projetos de museus e } \\
\text { exposições, } \\
\text { organizam acervos } \\
\text { museológicos públicos } \\
\text { e privados. Dão } \\
\text { acesso à informação, } \\
\text { conservam acervos. } \\
\text { Preparam ações } \\
\text { educativas ou } \\
\text { culturais, planejam e } \\
\text { realizam atividades } \\
\text { técnico- } \\
\text { administrativas, } \\
\text { orientam implantação } \\
\text { das as atividades } \\
\text { técnicas. Participam } \\
\text { da política de criação } \\
\text { e implantação de de } \\
\text { museus e instituições } \\
\text { arquivísticas. }\end{array}$} \\
\hline & & & arquivo médico e estatístico & \\
\hline & & & $\begin{array}{l}\text { Especialista de } \\
\text { documentação arquivística }\end{array}$ & \\
\hline & & & $\begin{array}{l}\text { Especialista em organização } \\
\text { de arquivos }\end{array}$ & \\
\hline & & & Gestor de documentos & \\
\hline & & \multirow[t]{6}{*}{ Museólogo } & Auxiliar de museus & \\
\hline & & & Conservador de museu & \\
\hline & & & $\begin{array}{l}\text { Especialista em } \\
\text { conservação de acervos }\end{array}$ & \\
\hline & & & \begin{tabular}{|l|} 
Especialista em \\
documentação museológica
\end{tabular} & \\
\hline & & & $\begin{array}{l}\text { Especialista em educação } \\
\text { em museus }\end{array}$ & \\
\hline & & & $\begin{array}{l}\text { Especialista em } \\
\text { museografia de exposição }\end{array}$ & \\
\hline
\end{tabular}

Fonte: Dados extraídos de Brasil (2003, p. 269 e 271) 


\section{QUADRO 2 - Pessoal ocupado em atividades de informação de nível} médio e administrativo segundo a Classificação Brasileira de Ocupações de 2002.

\begin{tabular}{|c|c|c|c|c|}
\hline Código & $\begin{array}{l}\text { Categoria } \\
\text { CBO }\end{array}$ & $\begin{array}{c}\text { Títulos } \\
\text { Ocupacionais }\end{array}$ & $\begin{array}{c}\text { Outras } \\
\text { denominações }\end{array}$ & Descrição Sumária \\
\hline \multirow[t]{7}{*}{3711} & \multirow{7}{*}{$\begin{array}{l}\text { Técnicos em } \\
\text { biblioteconom } \\
\text { ia }\end{array}$} & \multirow[t]{3}{*}{$\begin{array}{l}\text { Auxiliar de } \\
\text { biblioteca }\end{array}$} & $\begin{array}{l}\text { Assistente de } \\
\text { biblioteca }\end{array}$ & \multirow{7}{*}{$\begin{array}{l}\text { Atuam no tratamento, } \\
\text { recuperação e disseminação } \\
\text { da informação e executam } \\
\text { atividades especializadas e } \\
\text { administrativas relacionadas à } \\
\text { rotina de unidades ou centros } \\
\text { de documentação ou } \\
\text { informação, quer } \\
\text { no atendimento ao usuário, } \\
\text { quer na administração do } \\
\text { acervo, ou na manutenção de } \\
\text { bancos de dados. } \\
\text { Participam da gestão } \\
\text { administrativa, elaboração e } \\
\text { realização de projetos de } \\
\text { extensão cultural. Colaboram } \\
\text { no controle e na conservação } \\
\text { de equipamentos. Participam } \\
\text { de treinamentos e programas } \\
\text { de atualização. }\end{array}$} \\
\hline & & & $\begin{array}{l}\text { Auxiliar de } \\
\text { bibliotecário }\end{array}$ & \\
\hline & & & $\begin{array}{l}\text { Auxiliar de serviços } \\
\text { bibliotecários }\end{array}$ & \\
\hline & & \multirow{4}{*}{$\begin{array}{l}\text { Técnico em } \\
\text { biblioteconomia }\end{array}$} & Técnico de biblioteca & \\
\hline & & & $\begin{array}{l}\text { Técnico de } \\
\text { documentação e } \\
\text { informação }\end{array}$ & \\
\hline & & & $\begin{array}{l}\text { Técnico em } \\
\text { documentação }\end{array}$ & \\
\hline & & & $\begin{array}{l}\text { Tratador de } \\
\text { documentos } \\
\text { (biblioteconomia) }\end{array}$ & \\
\hline \multirow[t]{2}{*}{3712} & \multirow{2}{*}{$\begin{array}{l}\text { Técnicos em } \\
\text { museologia e } \\
\text { afins }\end{array}$} & $\begin{array}{l}\text { Colecionador de } \\
\text { selos e moedas }\end{array}$ & Numismata & \multirow{2}{*}{$\begin{array}{l}\text { Auxiliam especialistas das } \\
\text { diversas áreas de museus, nos } \\
\text { trabalhos de organização, } \\
\text { conservação, pesquisa e } \\
\text { difusão de documentos e } \\
\text { objetos de caráter histórico, } \\
\text { artístico, científico, literário ou } \\
\text { de outra natureza. }\end{array}$} \\
\hline & & $\begin{array}{l}\text { Técnico em } \\
\text { museologia }\end{array}$ & $\begin{array}{l}\text { Técnico de arquivo } \\
\text { (museologia) }\end{array}$ & \\
\hline \multirow[t]{6}{*}{4151} & \multirow{6}{*}{$\begin{array}{l}\text { Auxiliares de } \\
\text { serviços de } \\
\text { documentaçã } \\
\text { o, informação } \\
\text { e pesquisa }\end{array}$} & $\begin{array}{l}\text { Arquivista de } \\
\text { documentos }\end{array}$ & Arquivador & \multirow{6}{*}{$\begin{array}{l}\text { Organizam documentos e } \\
\text { informações. Orientam } \\
\text { usuários e os auxiliam na } \\
\text { recuperação de dados e } \\
\text { informações. Disponibilizam } \\
\text { fonte de dados para usuários. } \\
\text { Providenciam aquisção de } \\
\text { material e incorporam } \\
\text { material ao acervo. Arquivam } \\
\text { documentos, classificando-os } \\
\text { segundo critérios apropriados } \\
\text { para armazená-los es e } \\
\text { conservá-los. Prestam serviço } \\
\text { de comutação, alimentam } \\
\text { base de dados e elaboram } \\
\text { estatísticas. Executam tarefas } \\
\text { relacionadas à elaboração e } \\
\text { manutenção de arquivos, } \\
\text { podendo ainda, operar } \\
\text { equipamentos reprográficos, } \\
\text { recuperar e preservar as } \\
\text { informações por meio digital, } \\
\text { magnético ou papel. }\end{array}$} \\
\hline & & $\begin{array}{l}\text { Codificador de } \\
\text { dados }\end{array}$ & & \\
\hline & & Fitotecário & & \\
\hline & & Kardexista & Ficharista & \\
\hline & & $\begin{array}{l}\text { Operador de } \\
\text { máquina } \\
\text { copiadora } \\
\text { (exceto operador } \\
\text { de gráfica } \\
\text { rápida) } \\
\end{array}$ & $\begin{array}{l}\text { Copiador de } \\
\text { documentos }\end{array}$ & \\
\hline & & & $\begin{array}{l}\text { Operador de } \\
\text { máquina reprográfica }\end{array}$ & \\
\hline
\end{tabular}

Fonte: dados extraídos de Brasil (2003, p. 489, 491, 553). 


\section{Dimensionando o pessoal ocupado em atividades de informação}

Este tópico diz respeito ao número total de profissionais ligados ao trabalho com informação, segundo as categorias da Classificação Brasileira de Ocupações de 2002 (BRASIL, 2003), e selecionadas para este estudo.

TABELA 1 - Quantitativo e porcentagem de Profissionais por Categoria CBO

\begin{tabular}{lcc}
\hline \multicolumn{1}{c}{ Categorias CBO } & Quantitativo de Profissionais \\
\cline { 2 - 3 } & $\mathbf{n}$ & $\mathbf{\%}$ \\
\hline $\begin{array}{l}\text { Profissionais da Informação (Nível } \\
\text { Superior) }\end{array}$ & 10.896 & \\
$\begin{array}{l}\text { Outros Profissionais da Informação } \\
\text { Profissionais da Informação (Total) }\end{array}$ & 21.632 & $\mathbf{0 , 0 5 0 5}$ \\
\hline Arquivistas e Museólogos & 32.528 & $\mathbf{0 , 0 0 1 6}$ \\
\hline Técnicos em Biblioteconomia & 1.059 & $\mathbf{0 , 0 0 0 9}$ \\
\hline Técnicos em Museologia e afins & 636 & $\mathbf{0 , 0 0 0 3}$ \\
\hline $\begin{array}{l}\text { Auxiliares de Serviços de } \\
\text { Documentação, Informação e }\end{array}$ & 50.738 & $\mathbf{0 , 0 7 8 8}$ \\
Pesquisa & & \\
\hline $\begin{array}{l}\text { Outros Profissionais das Ciências e } \\
\text { Artes }\end{array}$ & 3.712 .417 & $\mathbf{5 , 7 6 5 9}$ \\
\hline Outros Ocupados & 60.587 .203 & $\mathbf{9 4 , 1 0 1 7}$ \\
\hline $\begin{array}{l}\text { TOTAL DA POPULAÇÃO } \\
\text { OCUPADA }\end{array}$ & 64.384 .786 & $\mathbf{1 0 0 , 0 0 0 0}$ \\
\hline
\end{tabular}

Fonte: Dados extraídos de Brasil (2003) e Instituto Brasileiro de Geografia e Estatística - IBGE (2003).

Nota: o total de Outros Ocupados e o total geral de ocupados do Censo Demográfico de 2000 só serão apresentados nesta tabela.

O grupo pessoal ocupado em atividades de informação compreendeu, de acordo com o processamento dos microdados do Censo Demográfico de 2000, um total de 85.166 pessoas ocupadas. Este número, diante do universo de ocupados, composto por 64.384.786 pessoas, é muito pequeno, pouco mais de $0,1 \%{ }^{*}$.

A TAB.1 mostra que, tratando-se de profissionais de nível superior, em quantidade, o Censo Demográfico de 2000 indica que os profissionais da informação são mais numerosos em relação aos seus colegas Arquivistas e Museólogos, com totais de 10.896 e 1.059 , respectivamente. $\mathrm{Em}$ relação aos profissionais de nível médio, os técnicos, a mesma tendência é verificada, com os Técnicos em Biblioteconomia tendo 636 profissionais e os de Museologia apenas 205 trabalhadores. O último grupo analisado, de nível administrativo, os Auxiliares de Serviços de Documentação, Informação e Pesquisa, em 2000, totalizavam 50.738

Tanto que foi preciso registrar as porcentagens usando-se quatro casas decimais depois da vírgula para que não se trabalhasse com zero\%. 
ocupados. Destaca-se que existem razões históricas para isso como a regulamentação das profissões, número de escolas etc.

Talvez um dos achados mais surpreendentes desta pesquisa seja a situação encontrada na categoria dos PI, pelo fato de a maioria dos profissionais - 21.632 pessoas que atuavam nessa categoria -, não possuir o nível de escolaridade compatível com o estabelecido pela CBO. Esse fato pode estar relacionado a um longo período de experiência acumulado por uma parcela desses profissionais na área de informação, porém, sem o grau de estudo necessário para ser reconhecido como um Profissional da Informação.

O título Profissional da Informação dá abertura à entrada de profissionais variados nessa classe. O próprio conceito de Profissional da Informação ainda não possui consenso na literatura da área de CI. Além disso, falta a esse grupo a regulamentação necessária por parte de órgãos fiscalizadores. Entende-se que todos esses fatores colaboraram para que a situação se apresentasse da forma como mostram os dados do Censo.

No trabalho de Jannuzzi e Mattos (2001) ${ }^{*}$, foi estabelecido um grupo que era composto por Bibliotecários, Arquivistas e Museólogos. Esse grupo possuía, em 1991, 11.601 profissionais. Comparativamente, somando-se o número de PI (efetivamente de nível superior) com o de Arquivistas e Museólogos, chega-se a 11.955 profissionais, um crescimento de apenas 354 pessoas em 9 anos. Aplicando-se a taxa de crescimento de 0,7\% proposta por Jannuzzi e Mattos (2001), para o grupo dos Bibliotecários, Arquivistas e Museólogos de 1991, chega-se a uma estimativa para o ano 2000 de 12.352 profissionais, número este que o Censo mostrou que não foi atingido, isto é, os microdados do Censo indicam que a categoria não cresceu o esperado.

\section{A distribuição de Pessoal Ocupado em Atividades de Informação pelas Regiões e Estados}

Quanto à distribuição do grupo estudado por região, como era de se esperar, ocorreu uma maior concentração de profissionais, de todas as categorias, na região Sudeste (TAB. 2, 3 e 4).

\footnotetext{
* Nessa pesquisa o total referia-se somente à jornada de trabalho total (40 horas ou mais) e nesta pesquisa, refere-se à jornada de trabalho total e parcial.
} 
TABELA 2 - Quantitativo de Profissionais, segundo a Categoria CBO, por Região.

\begin{tabular}{|c|c|c|c|c|c|c|c|}
\hline \multirow{2}{*}{$\begin{array}{l}\text { Regiões } \\
\text { e } \\
\text { Estados }\end{array}$} & \multicolumn{6}{|c|}{ Categorias CBO } & \multirow[b]{2}{*}{$\begin{array}{l}\text { Total de } \\
\text { PESSOAL } \\
\text { OCUPADO EM } \\
\text { ATIVIDADES } \\
\text { DE } \\
\text { INFORMAÇÃO }\end{array}$} \\
\hline & $\begin{array}{l}\text { Profissionai } \\
\text { s da } \\
\text { Informação } \\
\text { (Nível } \\
\text { Superior) } \\
\end{array}$ & $\begin{array}{l}\text { Outros } \\
\text { Profissionai } \\
\text { S da } \\
\text { Informação }\end{array}$ & $\begin{array}{l}\text { Arquivistas } \\
\mathrm{e} \\
\text { Museólogos }\end{array}$ & $\begin{array}{l}\text { Técnicos em } \\
\text { Bibliotecono } \\
\text { mia }\end{array}$ & $\begin{array}{l}\text { Técnicos } \\
\text { em } \\
\text { Museologia } \\
\text { e afins }\end{array}$ & $\begin{array}{l}\text { Auxiliares de } \\
\text { Serviços de } \\
\text { Documentação, } \\
\text { Informação e } \\
\text { Pesquisa }\end{array}$ & \\
\hline \multicolumn{8}{|c|}{$\mathbf{n}$} \\
\hline Norte & 532 & 2.021 & 32 & 42 & 31 & 2.785 & 5.443 \\
\hline Nordeste & 2.198 & 5.199 & 169 & 59 & 62 & 11.069 & 18.756 \\
\hline Sudeste & 5.353 & 8.537 & 583 & 381 & 88 & 25.667 & 40.609 \\
\hline $\mathrm{SP}$ & 2.353 & 3.749 & 176 & 144 & 42 & 11.629 & 18.093 \\
\hline RJ & 1.749 & 1.548 & 335 & 83 & 32 & 7.656 & 11.403 \\
\hline MG & 1.090 & 2.870 & 49 & 117 & 7 & 5.315 & 9.448 \\
\hline Sul & 1.968 & 4.287 & 194 & 119 & 21 & 6.643 & 13.232 \\
\hline PR & 594 & 1.951 & 74 & 15 & 0 & 2.216 & 4.850 \\
\hline RS & 910 & 1.306 & 68 & 83 & 21 & 3.154 & 5.542 \\
\hline $\begin{array}{l}\text { Centro } \\
\text { Oeste }\end{array}$ & 845 & 1.585 & 81 & 34 & 2 & 4.574 & 7.121 \\
\hline $\mathrm{DF}$ & 520 & 222 & 46 & 19 & 0 & 2.092 & 2.899 \\
\hline TOTAL & 10.896 & 21.629 & 1.059 & 635 & 204 & 50.738 & 85.161 \\
\hline
\end{tabular}

Fonte: Dados extraídos de Brasil (2003) e IBGE (2003).

As evidências empíricas da TAB. 2 mostram que os Outros Profissionais da Informação são mais numerosos que os PI de Nível Superior em quase todas as regiões, e que os primeiros totalizam quase que o dobro dos PI de Nível Superior da CBO. Observando-se casos como o do estado do Rio de Janeiro e do Distrito Federal, nota-se uma superioridade de PI de Nível Superior, em relação aos Outros Profissionais da Informação. Entende-se que o problema referente à autodeclaração de profissionais de nível médio como PI ocorre mais nas regiões menos desenvolvidas do país.

O Conselho Federal de Biblioteconomia (CFB) e o Conselho Federal de Museologia (Cofem), além dos Conselhos Regionais de Biblioteconomia e dos Conselhos Regionais de Museologia, foram consultados primeiramente via e-mail e, em alguns casos, via postal - para que fornecessem o número total de profissionais cadastrados em suas instituições, bem como o número de profissionais em atividade, isto é, o número de registros ativos. Vale observar que, após insistentes contatos, dos 22 órgãos consultados, somente 5 responderam.

De acordo com informações obtidas junto ao Corem $3^{a}$ Região, referente ao Rio Grande do Sul, o número informado* de profissionais Museólogos foi de 84, sendo, desse total, 39 profissionais com registro ativo. Comparando-se esse resultado ao total de Arquivistas e Museólogos encontrado no processamento dos microdados do Censo, com 68 profissionais, entende-se que os valores encontrados nesta pesquisa podem ser entendidos como um retrato fiel e próximo da realidade do mercado de trabalho nessas ocupações, dentro do erro amostral da pesquisa.

\footnotetext{
* Informações obtidas via e-mail em 24/9/2004.
} 
TABELA 3 - Porcentagem de Profissionais, segundo a Região, por Categoria CBO.

\begin{tabular}{|c|c|c|c|c|c|c|c|}
\hline \multirow{3}{*}{$\begin{array}{c}\text { Regiões } \\
\text { e } \\
\text { Estados }\end{array}$} & \multicolumn{6}{|c|}{ Categorias CBO } & \multirow[b]{2}{*}{$\begin{array}{c}\text { Total de } \\
\text { PESSOAL } \\
\text { OCUPADO } \\
\text { EM } \\
\text { ATIVIDADES } \\
\text { DE } \\
\text { INFORMA- } \\
\text { ÇÃO } \\
\end{array}$} \\
\hline & $\begin{array}{l}\text { Profissionais da } \\
\text { Informação } \\
\text { (Nível Superior) }\end{array}$ & $\begin{array}{l}\text { Outros } \\
\text { Profissionais } \\
\text { da } \\
\text { Informação }\end{array}$ & $\begin{array}{l}\text { Arquivistas } \\
\text { e } \\
\text { Museólogos }\end{array}$ & $\begin{array}{l}\text { Técnicos em } \\
\text { Bibliotecono } \\
\text { mia }\end{array}$ & $\begin{array}{l}\text { Técnicos } \\
\text { em } \\
\text { Museologia } \\
\text { e afins }\end{array}$ & $\begin{array}{l}\text { Auxiliares de } \\
\text { Serviços de } \\
\text { Documentaçã } \\
\text { o, Informação } \\
\text { e Pesquisa }\end{array}$ & \\
\hline & \multicolumn{7}{|c|}{$\%$} \\
\hline Norte & 4,8 & 9,3 & 3,0 & 6,6 & 15,2 & 5,4 & 6,4 \\
\hline Nordeste & 20,1 & 24,0 & 15,9 & 9,2 & 30,4 & 21,8 & 22,0 \\
\hline Sudeste & 49,1 & 39,4 & 55,0 & 60,0 & 43,1 & 50,5 & 47,6 \\
\hline Sul & 18,0 & 19,8 & 18,3 & 18,7 & 10,3 & 13,1 & 15,5 \\
\hline $\begin{array}{l}\text { Centro } \\
\text { Oeste }\end{array}$ & 7,7 & 7,3 & 7,6 & 5,3 & 0,9 & 9,0 & 8,3 \\
\hline TOTAL & 100,0 & 100,0 & 100,0 & 100,0 & 100,0 & 100,0 & 100,0 \\
\hline
\end{tabular}

Fonte: Dados extraídos de Brasil (2003) e IBGE (2003).

De acordo com informações fornecidas pelo Conselho Regional de Biblioteconomia -CRB-1a Região**, que engloba as unidades federadas de Goiás, Mato Grosso, Mato Grosso do Sul e Distrito Federal, o número total de profissionais inscritos nesse órgão é de 2014, sendo 1182 registros ativos. Entende-se que os números encontrados no Censo se referem a uma amostragem da população ocupada, e, por esta razão, constata-se uma proximidade entre os dois resultados.

Entretanto, causa estranheza o fato de o número total do cadastro desse órgão chegar perto do número de profissionais juntando-se os de nível superior efetivos e os Outros PI, que não possuem escolaridade superior. Seguindo essa linha de raciocínio, como estaria a fiscalização em relação à comprovação de estudo e nível profissional pelas instituições fiscalizadoras? Ou, ainda, estariam os cadastros dos CRBs, na melhor das situações, precisando de revisões?

O grupo pessoal ocupado em atividades de informação ficou distribuído, entre as regiões brasileiras, da seguinte forma: 6,4\% na região Norte; $22,0 \%$ na região Nordeste; $47,6 \%$ na região Sudeste; $15,5 \%$ na região Sul e $8,3 \%$ na região Centro-Oeste.

Confirmando a hipótese, a maior concentração de PI (de Nível Superior) ficou na região Sudeste, com 49,1\% desses profissionais. Em relação ao número de PI em São Paulo (2.353 pessoas), comparou-se esse resultado com dados informados pelo CRB 8 a região, de São Paulo*, que forneceu o total de cadastrados nesse órgão, com 7.672 pessoas, sem destacar o número de registros ativos.

Foi também na região Sudeste onde se concentrou a maior parcela dos Arquivistas e Museólogos em 2000 (55,0\%). Quanto aos ocupados de nível médio, os Técnicos em Biblioteconomia, a maioria encontra-se na região Sudeste $(60,0 \%)$; quanto aos Técnicos em Museologia e afins

** Dados fornecidos via e-mail em 13/9/2004. 
chama a atenção sua concentração nas Regiões Sudeste $(43,1 \%)$ e Nordeste $(30,3 \%)$.

Já os Auxiliares de Serviços de Documentação, Informação e Pesquisa, de nível administrativo, se dividiram em $5,4 \%$ na região Norte; $21,8 \%$ na região Nordeste; $50,5 \%$ na região Sudeste; $13,0 \%$ na região Sul e 9,0\% na região Centro-Oeste.

De todos os resultados apresentados nas Tabelas 2 e 3, chama a atenção, em relação aos Profissionais da Informação (de Nível Superior), a concentração na região Nordeste, com 2.198 pessoas $(20,1 \%)$. Na introdução desta pesquisa colocou-se a hipótese de que a inserção desses profissionais seria mais alta em estados como São Paulo, Rio de Janeiro, Rio Grande do Sul e principais capitais do país. Comparando-se a região Nordeste e a Sul, percebe-se uma diferença pequena, tendo a Nordeste $20,1 \%$ dos profissionais e a Sul 18,0\%. Esse resultado aponta para um aparente paradoxo, pois, apesar de a região Nordeste possuir uma maior população e capitais dinâmicas, como Fortaleza e Salvador, possui áreas de extrema pobreza, comparando-se com a região Sul, de forma geral. O aparente paradoxo é dirimido com a comparação dos dados da Tabela 4, na qual se apresenta a razão de profissionais pelas regiões por 100 mil habitantes, a fim de permitir a comparação das condições de oferta de profissionais, tendo em vista os diferentes volumes populacionais.

TABELA 4 - Razão de Profissionais por 100 mil habitantes, segundo a Categoria CBO, por Região

\begin{tabular}{|c|c|c|c|c|c|c|}
\hline \multirow{3}{*}{$\begin{array}{l}\text { Categorias } \\
\text { CBO }\end{array}$} & \multicolumn{5}{|c|}{ Regiões e Estados } & \multirow[t]{3}{*}{ TOTAL } \\
\hline & Norte & Nordeste & Sudeste & Sul & $\begin{array}{c}\text { Centro } \\
\text { Oeste }\end{array}$ & \\
\hline & \multicolumn{5}{|c|}{100.000 habitantes } & \\
\hline $\begin{array}{l}\text { Profissionais da } \\
\text { Informação (Nível } \\
\text { Superior) }\end{array}$ & 4,1 & 4,6 & 7,3 & 7,8 & 7,2 & 31 \\
\hline $\begin{array}{l}\text { Outros } \\
\text { Profissionais da } \\
\text { Informação }\end{array}$ & 15,6 & 10,8 & 11,7 & 17,0 & 13,6 & 68,7 \\
\hline $\begin{array}{l}\text { Arquivistas e } \\
\text { Museólogos }\end{array}$ & 0,2 & 0,3 & 0,8 & 0,7 & 0,6 & 2,6 \\
\hline $\begin{array}{l}\text { Técnicos em } \\
\text { Biblioteconomia }\end{array}$ & 0,3 & 0,1 & 0,5 & 0,4 & 0,2 & 1,5 \\
\hline $\begin{array}{l}\text { Técnicos em } \\
\text { Museologia e afins }\end{array}$ & 0,2 & 0,1 & 0,1 & 0,08 & 0,01 & 0,4 \\
\hline $\begin{array}{l}\text { Auxiliares de } \\
\text { Serviços de } \\
\text { Documentação, } \\
\text { Informação e } \\
\text { Pesquisa }\end{array}$ & 21,5 & 23,1 & 35,4 & 26,4 & 39,3 & 145,7 \\
\hline TOTAL & 42,1 & 39,2 & 56,0 & 52,7 & 61,1 & 249,9 \\
\hline
\end{tabular}

Fonte: Dados extraídos de Brasil (2003) e IBGE (2003) 
Em relação especificamente ao número de Profissionais da Informação de nível superior, comparando-se os números das regiões Nordeste e Sul, percebe-se grande concentração de profissionais na região Sul, considerando que, esta última, possui uma população bem menor que a da região Nordeste.

De acordo com informações coletadas no site do IBGE (IBGE, 2004), no Censo de 2000 a população total no Brasil era de 169.799.170 pessoas. Desse total, apenas 85.166 delas compõem o grupo objeto de estudo desta pesquisa, isto é, trabalhavam de alguma forma com informação.

Considerando que cada empresa de médio e grande porte lida com um volume de documentos significativo, pode-se entender que deveria existir um campo de trabalho maior para os Arquivistas. Não é o que os dados do Censo mostram: a realidade do grupo composto pelos Arquivistas e Museólogos é ruim para os profissionais de nível superior. No ranking das regiões a ordem seria a região Sudeste em primeiro lugar, com 0,8 profissionais a cada 100 mil habitantes; seguida da região Sul (com 0,7$)$, Centro-Oeste $(0,6)$, Nordeste $(0,3)$ e Norte $(0,2)$. Faz-se uma ligação desses resultados com a pouca visibilidade da categoria profissional, de maneira geral.

\section{As características sócio-demográficas do grupo pessoal ocupado em atividades de informação}

Em relação às características sociodemográficas destaca-se a escolaridade, por se tratar de um indicador significativo para essa discussão, além de o mesmo ser considerado clássico em estudos dessa natureza (JANNUZZI, 2003).

A escolaridade também foi dividida em faixas (anos completos de estudo) que correspondem, respectivamente, ao ensino médio; superior incompleto e superior completo. A TAB. 5 apresenta os resultados encontrados: 
TABELA 5 - Número e porcentagem de Profissionais, segundo a Categoria CBO, por Escolaridade

\begin{tabular}{|c|c|c|c|c|c|c|c|c|}
\hline \multirow[t]{3}{*}{ Categorias CBO } & \multicolumn{6}{|c|}{$\begin{array}{c}\text { Escolaridade } \\
\text { (anos completos de estudo) }\end{array}$} & \multirow{2}{*}{\multicolumn{2}{|c|}{ TOTAL }} \\
\hline & \multicolumn{2}{|c|}{ Até 11 anos } & \multicolumn{2}{|c|}{ De 12 a 14 anos } & \multicolumn{2}{|c|}{15 ou mais } & & \\
\hline & $\mathbf{n}$ & $\%$ & $\mathbf{n}$ & $\%$ & $\mathbf{N}$ & $\%$ & $\mathbf{n}$ & $\%$ \\
\hline $\begin{array}{l}\text { Profissionais da } \\
\text { Informação }\end{array}$ & 15.912 & 48,9 & 5.720 & 17,5 & 10.896 & 33,4 & 32.528 & 100,0 \\
\hline $\begin{array}{l}\text { Arquivistas e } \\
\text { Museólogos }\end{array}$ & 288 & 27,1 & 140 & 13,2 & 631 & 59,5 & 1.059 & 100,0 \\
\hline $\begin{array}{l}\text { Técnicos em } \\
\text { Biblioteconomia }\end{array}$ & 373 & 58,6 & 137 & 21,5 & 126 & 19,8 & 636 & 100,0 \\
\hline $\begin{array}{l}\text { Técnicos em Museologia } \\
\text { e afins }\end{array}$ & 112 & 54,9 & 33 & 16,1 & 59 & 28,9 & 204 & 100,0 \\
\hline $\begin{array}{l}\text { Auxiliares de Serviços } \\
\text { de Documentação, } \\
\text { Informação e Pesquisa }\end{array}$ & 40.898 & 80,6 & 5.231 & 10,3 & 4.609 & 9,0 & 50.738 & 100,0 \\
\hline $\begin{array}{l}\text { Outros Profissionais das } \\
\text { Ciências e Artes }\end{array}$ & 958.904 & 25,8 & 455.485 & 12,2 & 2.298 .032 & 61,9 & 3.712 .421 & 100,0 \\
\hline TOTAL* & $\mathbf{5 7 . 5 8 3}$ & 67,6 & 11.261 & 13,2 & 16.321 & 19,1 & 85.165 & 100,0 \\
\hline
\end{tabular}

Fonte: Dados extraídos de Brasil (2003) e IBGE... (2003).

Nota: Até 11 anos de estudo corresponde ao Ensino Médio; De 12 a 14 anos ao Ensino Superior Incompleto; e De 15 anos ou mais ao Ensino Superior Completo.

(*) Nota: Esse total diz respeito ao grupo 'pessoal ocupado em atividades de informação', não incluindo, na soma, a classe Outros Profissionais das Ciências e Artes.

Em relação aos dados encontrados, o maior achado, como foi anteriormente destacado, foi o fato de haver uma grande concentração de profissionais que declararam ocupar postos de trabalho classificados da forma como os que a CBO classifica como Profissionais da Informação na entrevista do Censo 2000, mas que não possuem nível de escolaridade compatível com o exigido para esse tipo de trabalho, segundo a própria CBO. Vale lembrar que as informações obtidas pelos entrevistadores do Censo resultam da declaração direta dos indivíduos na data da coleta de dados. Esse fator interfere nos números encontrados, pois podem existir casos em que uma pessoa desempenha duas funções diferentes e, quando da entrevista, ela terá de optar por uma delas, sendo contabilizada no grupo profissional a que deu ênfase e preferência.

Chamam a atenção resultados como os encontrados para os técnicos (19,8\% para os Técnicos em Biblioteconomia, por exemplo) e auxiliares ( $9,0 \%$ com nível superior completo). Pode-se questionar por que um profissional que possui nível superior se auto-afirma técnico ou auxiliar em uma pesquisa como o Censo? Não deveria essa pessoa se incluir na faixa com maior nível de escolaridade que possui?

Entende-se que o que pode ter influenciado as respostas dos entrevistados seja o tipo de função que eles exerciam em seus empregos na data da entrevista do Censo: por exemplo, nem todos os profissionais que possuem nível superior trabalham em cargos ou funções que estejam ligados a essa formação. Por essa razão, sendo fiéis ao tipo de ocupação que estão desempenhando, vários respondentes se incluíram nas faixas de acordo com o cargo ou função a que estavam ligados na época de entrevista do Censo. 
Destaca-se ainda, para os profissionais de nível superior, a porcentagem de PI com mais de 15 anos de estudo $(33,4 \%)$ e a do grupo dos Arquivistas e Museólogos (59,5\%). Comparando-se esses resultados, pode-se entender que o grupo dos Arquivistas e Museólogos, apesar de contar com um número bem menor de profissionais do que o grupo dos PI de nível superior, tem enfrentado menos problemas quanto à compatibilidade do nível escolar com as atividades desenvolvidas.

Tratando-se ainda dos PI de nível superior, vale lembrar que o BLS fornece pontos significativos em relação ao perfil dos librarians como: pós-graduação usualmente requerida em Biblioteconomia; necessidade de possuir uma graduação adicional; e uso das tecnologias de informação para desenvolver suas atividades, entre elas, pesquisas, classificação de materiais e assistência a usuários (BUREAU..., 2004a). Esse assunto já foi amplamente discutido em Loureiro (2004). É importante destacar que, comparando-se Brasil e Estados Unidos, vê-se claramente a diferença em relação à formação cultural dos profissionais que atuam no tratamento da informação, quando se coloca a exigência de um curso de graduação na área em que determinado profissional vai atuar, para que o mesmo seja capaz de entender e dominar conceitos importantes daquela área do conhecimento, sendo, assim, mais eficiente no seu trabalho de organização da informação e do conhecimento.

De qualquer forma, entende-se que as profissões ligadas à informação requerem, até pelo seu objeto de trabalho, um nível de estudo mais elevado, quando comparado a outras atividades profissionais como os enfermeiros, por exemplo.

\section{Indicadores de Inserção Ocupacional}

Como indicadores de inserção ocupacional, para esta pesquisa, foram selecionados a posição na ocupação e o rendimento médio (Tabelas 6,7 e 8).

As categorias estabelecidas no Censo foram as seguintes: 1) empregado com carteira assinada e empregado sem carteira assinada; 2) integrantes do Regime Jurídico dos Funcionários Públicos ou Militares; 3) autônomo; 4) empregador; e 5) outros (categoria na qual se incluem, basicamente, aprendizes e estagiários). 
TABELA 6 - Número de Profissionais, segundo a Categoria CBO, por Posição na Ocupação

\begin{tabular}{|c|c|c|c|c|c|c|c|}
\hline \multirow{4}{*}{$\begin{array}{l}\text { Categorias } \\
\text { CBO }\end{array}$} & \multicolumn{6}{|c|}{ Posição na Ocupação } & \multirow[t]{3}{*}{ TOTAL } \\
\hline & \multicolumn{2}{|c|}{ Empregado } & \multirow{2}{*}{$\begin{array}{l}\text { RJFP* } \\
\text { Militar }\end{array}$} & \multirow[t]{2}{*}{ Autônomo } & \multirow[t]{2}{*}{ Empregador } & \multirow[t]{2}{*}{ Outros } & \\
\hline & $\begin{array}{c}\text { Com } \\
\text { Carteira } \\
\text { Assinada }\end{array}$ & $\begin{array}{c}\text { Sem } \\
\text { Carteira } \\
\text { Assinada }\end{array}$ & & & & & \\
\hline & & & & $\mathbf{N}$ & & & \\
\hline $\begin{array}{l}\text { Profissionais da } \\
\text { Informação } \\
\text { (Nível Superior) }\end{array}$ & 6.414 & 652 & 3.802 & 0 & 0 & 28 & 10.896 \\
\hline $\begin{array}{l}\text { Outros } \\
\text { Profissionais da } \\
\text { Informação }\end{array}$ & 10.740 & 4.142 & 6.395 & 0 & 0 & 355 & 21.632 \\
\hline $\begin{array}{l}\text { Arquivistas e } \\
\text { Museólogos }\end{array}$ & 447 & 191 & 277 & 126 & 0 & 18 & 1.059 \\
\hline $\begin{array}{l}\text { Técnicos em } \\
\text { Biblioteconomia }\end{array}$ & 238 & 151 & 223 & 0 & 0 & 25 & 637 \\
\hline $\begin{array}{l}\text { Técnicos em } \\
\text { Museologia e } \\
\text { afins }\end{array}$ & 51 & 34 & 30 & 74 & 0 & 16 & 205 \\
\hline $\begin{array}{l}\text { Auxiliares de } \\
\text { Serviços de } \\
\text { Documentação, } \\
\text { Informação e } \\
\text { Pesquisa }\end{array}$ & 28.496 & 10.408 & 8.005 & 3.024 & 0 & 803 & 50.736 \\
\hline $\begin{array}{l}\text { Outros } \\
\text { Profissionais } \\
\text { das Ciências e } \\
\text { Artes }\end{array}$ & 1.407 .507 & 498.215 & $\begin{array}{c}644.31 \\
6\end{array}$ & 906.866 & 200.254 & 54.561 & $\begin{array}{c}3.711 .7 \\
19\end{array}$ \\
\hline TOTAL** & 46.386 & 15.578 & 18.732 & 3.224 & 0 & 1.245 & 85.165 \\
\hline
\end{tabular}

Fonte: Dados extraídos de Brasil (2003) e IBGE (2003).

$\left.{ }^{*}\right)$ Nota: Regime Jurídico dos Funcionários Públicos.

$(* *)$ Nota: esse total se refere ao grupo 'pessoal ocupado em atividades de informação', não incluindo o grupo Outros Profissionais das Ciências e Artes.

Os dados do Censo mostraram que no grupo 'pessoal ocupado em atividades de informação', em 2000, não havia nenhum empregador. Esse resultado deve ser analisado com cautela, não podendo ser considerado tão alarmante quanto parece, já que o Censo questiona a atividade que o profissional desenvolve naquela data. Por exemplo, o caso de um microempresário, que possua dois ou três empregados seria incluído como Dirigente de empresas e organizações, membro do Grande Grupo 1 da CBO, fugindo, nesse caso, de sua formação. Para se detectar o número de profissionais ligados à informação que estivessem em situações como a do exemplo citado, seria preciso investigar e cruzar o último curso concluído para tentar mapear esses profissionais, o que poderá ser desenvolvido em estudo posterior.

A maior concentração de PI de nível superior, em 2000, era de empregados com carteira assinada (6.414 pessoas), seguida de funcionários públicos e militares com 3.802 profissionais. 
TABELA 7 - Porcentagem de Profissionais, segundo a Categoria CBO, por Posição na Ocupação

\begin{tabular}{|c|c|c|c|c|c|c|c|}
\hline \multirow{3}{*}{$\begin{array}{c}\text { Categorias } \\
\text { CBO }\end{array}$} & \multicolumn{6}{|c|}{ Posição na Ocupação } & \multirow[t]{3}{*}{ TOTAL } \\
\hline & \multicolumn{2}{|c|}{ Empregado } & \multirow{2}{*}{$\begin{array}{l}\text { RJFP*/ } \\
\text { Militar }\end{array}$} & \multirow[t]{2}{*}{ Autônomo } & \multirow[t]{2}{*}{ Empregador } & \multirow[t]{2}{*}{ Outros } & \\
\hline & $\begin{array}{c}\text { Com } \\
\text { Carteira } \\
\text { Assinada }\end{array}$ & $\begin{array}{c}\text { Sem } \\
\text { Carteira } \\
\text { Assinada }\end{array}$ & & & & & \\
\hline & & & & $\%$ & & & \\
\hline $\begin{array}{l}\text { Profissionais da } \\
\text { Informação } \\
\text { (Nível Superior) }\end{array}$ & 58,8 & 6,0 & 34,8 & 0 & 0 & 0,2 & 100,0 \\
\hline $\begin{array}{l}\text { Outros } \\
\text { Profissionais da } \\
\text { Informação }\end{array}$ & 49,6 & 19,1 & 29,5 & 0 & 0 & 1,6 & 100,0 \\
\hline $\begin{array}{l}\text { Arquivistas e } \\
\text { Museólogos }\end{array}$ & 42,2 & 18,0 & 26,1 & 11,8 & 0 & 1,7 & 100,0 \\
\hline $\begin{array}{l}\text { Técnicos em } \\
\text { Biblioteconomia }\end{array}$ & 37,3 & 23,7 & 35,0 & 0 & 0 & 3,9 & 100,0 \\
\hline $\begin{array}{l}\text { Técnicos em } \\
\text { Museologia e } \\
\text { afins }\end{array}$ & 24,8 & 16,5 & 14,6 & 36,0 & 0 & 7,8 & 100,0 \\
\hline $\begin{array}{l}\text { Auxiliares de } \\
\text { Serviços de } \\
\text { Documentação, } \\
\text { Informação e } \\
\text { Pesquisa }\end{array}$ & 56,1 & 20,5 & 15,7 & 5,9 & 0 & 1,5 & 100,0 \\
\hline $\begin{array}{l}\text { Outros } \\
\text { Profissionais das } \\
\text { Ciências e Artes }\end{array}$ & 37,9 & 13,4 & 17,3 & 24,4 & 5,3 & 1,4 & 100,0 \\
\hline TOTAL** & 54,4 & 18,2 & 22,0 & 3,7 & - & 1,4 & 100,0 \\
\hline
\end{tabular}

Fonte: Dados extraídos de Brasil (2003) e IBGE (2003).

$\left(^{*}\right)$ Nota: Regime Jurídico dos Funcionários Públicos.

$(* *)$ Nota: esse total se refere ao grupo 'pessoal ocupado em atividades de informação' não incluindo o grupo Outros Profissionais das Ciências e Artes.

Ainda em relação aos PI (de Nível Superior), vale salientar a inexistência de profissionais autônomos tanto nessa categoria como no grupo dos Outros Profissionais da Informação. Os resultados mostram que o tipo de relação contratual predominante dos PI é melhor, pois a maioria é de empregados com carteira assinada ou funcionários do Regime Jurídico dos Funcionários Públicos.

Mesmo com os problemas já discutidos em relação à grande concentração de profissionais no grupo dos Outros Profissionais da Informação - isto é, pessoas que não possuem o nível escolar compatível com as atividades que, aparentemente, executam -, é importante observar, diante das porcentagens apresentadas na TAB. 7, como o nível superior torna-se um diferencial para se inserir no grupo dos profissionais empregados e com carteira assinada.

Já no caso dos Arquivistas e Museólogos, embora o maior número de profissionais seja o grupo de empregados com carteira assinada $(42,2 \%)$, devem-se destacar os $11,8 \%$ de profissionais que atuavam, em 
2000, como autônomos, diferentemente dos PI de nível superior, como foi discutido acima.

Entre os profissionais de nível técnico, merecem destaque os Técnicos em Museologia e afins com 36,0\% de profissionais na categoria dos autônomos. Seria esta grande concentração de profissionais ligados aos trabalhos de arquivos e museus, como autônomos, um indicador de maior independência no exercício da ocupação do que a dos PI de nível superior (ou bibliotecários)? Estaria essa atitude ligada ao tipo de trabalho executado? Estariam essas duas vertentes pendendo para uma atitude mais empreendedora em relação aos PI de nível superior?

O grupo dos Auxiliares de Serviços de Documentação, Informação e Pesquisa possuía a maior parte de seus profissionais como empregados com carteira assinada $(56,1 \%)$; seguida dos empregados sem carteira assinada $(20,5 \%)$ e com $15,7 \%$ dos profissionais como funcionários públicos ou militares.

De acordo com Jannuzzi (2001, p. 93), dentre os indicadores para estudos de mercado de trabalho, o rendimento médio é um dos mais significativos, sendo sensível às variações conjunturais da economia, da produção industrial e nível da inflação observada. O mesmo autor destaca ainda que o rendimento do trabalho corresponde, para os assalariados, de forma geral, à remuneração bruta efetivamente recebida no mês anterior à pesquisa, que inclui salários, abonos e gratificações. Já no caso dos trabalhadores autônomos e empregadores, corresponde à retirada ou ao ganho líquido realizado no mês anterior. Não são considerados rendimento os benefícios adicionais em espécie ou em dinheiro, como cesta de alimentos, vale-transporte, vale-refeição ou plano de saúde.

$\mathrm{Na}$ TAB. 8 são apresentados os dados apontados pelo Censo 2000 em relação ao rendimento médio do grupo 'pessoal ocupado em atividades de informação': 
TABELA 8 - Número e porcentagem de Profissionais, segundo a Categoria CBO, por Rendimento Médio. Brasil, 2000.

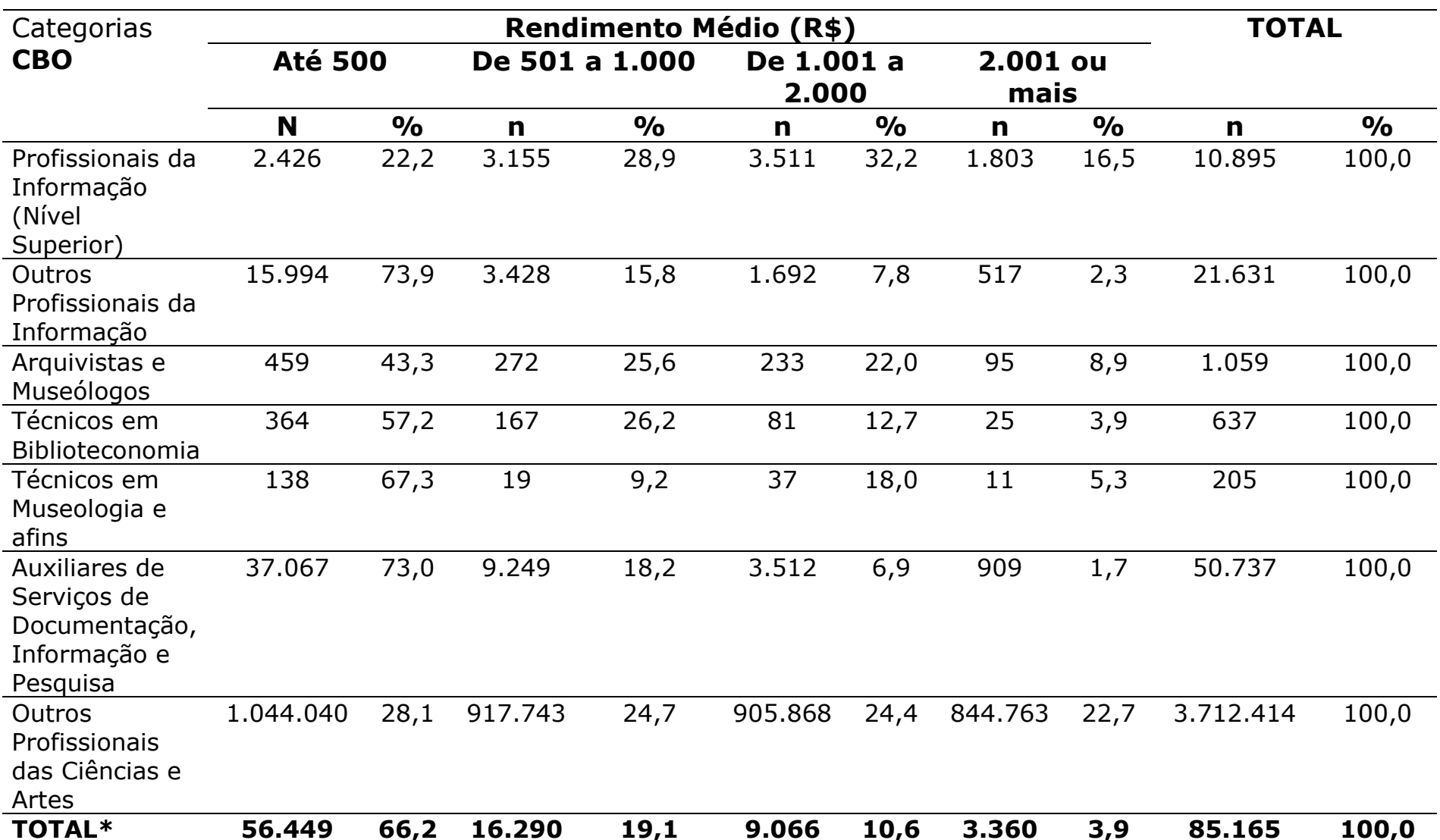

Fonte: Dados extraídos de Brasil (2003) e IBGE (2003)

(*) Nota: Esse total diz respeito ao grupo 'pessoal ocupado em atividades de informação', não incluindo na soma, a classe Outros Profissionais das Ciências e Artes.

Para se tratar o rendimento médio foram estabelecidas quatro faixas de remuneração: 1 ) até $\mathrm{R} \$ 500,00 ; 2)$ de $\mathrm{R} \$ 501,00$ a $1.000,00 ; 3)$ de $\mathrm{R} \$$ $1.001,00$ a $2.000,00$; e, 4) $\mathrm{R} \$ 2.001,00$ ou mais. Vale ressaltar que não houve, aqui, diferenciação de profissionais com relação à carga horária trabalhada, sendo este o rendimento do trabalho principal.

Assim, segundo os microdados do Censo 2000, a maior concentração de PI (de nível superior) está na faixa de R\$1.001,00 a $2.000,00$, com $32,2 \%$, seguida de perto pelos profissionais da faixa de $\mathrm{R} \$$ 501,00 a 1.000,00, com 28,9\%. Causou estranheza uma faixa dos profissionais de nível superior estar inserida na faixa com remuneração até $\mathrm{R} \$ 500,00(22,2 \%)$.

Já em relação aos Outros Profissionais da Informação, grupo encontrado com nível de escolaridade inferior ao superior completo, destaca-se a grande concentração de profissionais na faixa de rendimento de Até $\mathrm{R} \$ 500,00$, com 73,9\% dos profissionais. Entende-se ser esse um indicador da precariedade a que esses profissionais estão submetidos e, pelo fato de serem reconhecidos como PI, poderão acarretar à categoria uma visibilidade inferior à sua realidade. Causou surpresa ainda, nesse grupo, a pequena, porém existente, concentração de 2,3\% de profissionais com salários acima de $\mathrm{R} \$ 2.000,00$. Faz-se essa referência 
apoiando-se em Fligenspan (2003), que ressalta que entre as diferentes variáveis que justificam os diferenciais salariais no Brasil, encontra-se a escolaridade.

Para os Arquivistas e Museólogos o maior grupo ficou na faixa de rendimento de até $R \$ 500,00$, com 43,3\%. Esse achado também pode ser considerado inferior ao esperado, pois essa categoria é efetivamente composta por pessoal de nível superior. Será o tipo de trabalho que não é reconhecido e, conseqüentemente, bem remunerado no mercado?

Conforme o esperado, os Técnicos em Biblioteconomia, os Técnicos em Museologia e afins e os Auxiliares de Serviços de Documentação, Informação e pesquisa tiveram as maiores concentrações na faixa de remuneração de até $\mathrm{R} \$ 500,00$, com 57,2\%, 67,3\% e 73,0\%, respectivamente. Ainda que esse resultado seja considerado esperado para esses grupos, devido a seu menor nível de escolaridade, surgiram pequenas concentrações dos três grupos na faixa de remuneração de $R$ \$ 2.001,00 ou mais. Esses achados ficam difíceis de ser explicados e, talvez, esse fosse um tema interessante para pesquisas futuras.

\section{Conclusão}

$\mathrm{Na}$ atualidade o trabalho tem sido objeto de interesse crescente e tem levado cada vez mais pesquisadores a desenvolverem estudos sobre este tema, mostrando que este assunto continua tendo grande ênfase no mundo todo.

Esta pesquisa partiu da hipótese de que, no Brasil, os profissionais que trabalhavam com informação estavam bem inseridos no mercado de trabalho, mesmo considerando-se possíveis influências das políticas econômicas. Entendia-se, ainda, que essa inserção não se dava de maneira uniforme e que seria mais intensa nos estados mais desenvolvidos, como São Paulo, Rio de Janeiro, Rio Grande do Sul e, também, nas principais capitais.

De fato, entre as regiões, constatou-se uma maior concentração de profissionais na região Sudeste, porém, de forma geral, este estudo constatou que a inserção de pessoal ocupado em atividades de informação, segundo os microdados do Censo Demográfico de 2000, não pode ser considerada muito melhor em relação ao total de ocupados do país e, também, em relação ao total da população.

Quanto aos objetivos específicos, o dimensionamento do contingente de profissionais do grupo pessoal ocupado em atividades de informação, que atuava no mercado de trabalho no ano 2000, é de 0,1\%, em relação ao total da população ocupada. Este resultado demonstrou o quanto esse grupo precisa melhorar, principalmente, comparando-se com os dados dos Estados Unidos.

Quanto ao rendimento, os dados mostraram que 66,2\% do grupo objeto de estudo desta pesquisa têm um rendimento médio de até $\mathrm{R} \$$ 500,00 , isto é, apesar de a maioria das categorias que compõem o grupo 'pessoal ocupado em atividades de informação' possuir nível escolar médio ou superior incompleto, mesmo assim os rendimentos são baixos, 
considerando-se todas as discussões a respeito da sociedade da informação e do conhecimento como um período em que haveria crescimento e valorização das profissões ligadas a conteúdos informacionais.

Quanto à posição na ocupação, mesmo com o contexto geral no campo do emprego convivendo com bruscas mudanças - podendo-se até pensar em uma mudança de paradigma, do trabalho com carteira assinada e estabilidade mais comum na década de 1980, para formas diferenciadas de relações trabalhistas, com contratos com prazo limitado, locação de serviços, etc. - constatou-se, a partir dos microdados do Censo Demográfico de 2000, que o grupo pessoal ocupado em atividades de informação se mantém no perfil tradicional, com a maioria dos seus ocupados atuando como empregados com carteira assinada ou como funcionários públicos.

A grande concentração de pessoal de nível médio que se autoclassifica como Profissional da Informação foi um dos achados mais importantes deste estudo. Entende-se a necessidade de que outras pesquisas sejam feitas nesse sentido para que mais discussões possam levar a categoria a se firmar e se expandir no mercado de trabalho brasileiro.

É muito importante a intensificação da fiscalização pelos conselhos da área, além do desenvolvimento de um trabalho de conscientização dos empregadores tanto em relação aos próprios serviços desenvolvidos pelos Profissionais da Informação - visando um aumento da inserção desses profissionais -, como também para que esses mesmos empregadores exijam o nível de escolaridade apropriado para o tipo de atividade executada por um profissional da informação.

É preciso que a categoria dos PI, como um todo, desenvolva mais uma atitude crítica em seus profissionais. Entende-se que essa atitude advém, basicamente, de um nível de escolaridade mais elevado. A intenção é melhorar o nível e a visibilidade da área e dos profissionais que nela atuam, trazendo benefícios para todos. Além disso, muito se discute nos dias atuais sobre a educação continuada como ponto fundamental para a manutenção do emprego num mercado de trabalho cada vez mais concorrido.

Entende-se que a CBO é uma ferramenta que deveria ser mais utilizada em estudos sobre o mercado de trabalho. No caso deste estudo, seu uso foi considerado satisfatório. Discutindo-se sobre o conceito de Profissional da Informação de acordo com a CBO, pode-se entender que, na prática, esse grupo é, basicamente, composto pelos bibliotecários, posição também sustentada por Cunha e Crivellari (2004).

\section{Agradecimentos}

Agradecemos à Coordenação de Aperfeiçoamento de Pessoal de Nível Superior (Capes) pela bolsa de estudo, a qual possibilitou o desenvolvimento da pesquisa, e a Marcos Franco Bueno, mestre em 
Ciência da Informação pela PUC-Campinas, pela organização prévia da base de dados do Censo Demográfico 2000.

\section{Referências}

BORGES, M. A. G. O profissional da informação: somatório de formações, competências e habilidades. In: BAPTISTA, S. G.; MUELLER, S. P. M. (Orgs.). Profissional da informação: o espaço de trabalho. Brasília: Thesaurus, 2004. p. 55-69. (Estudos avançados em Ciência da Informação, v. 3).

BRASIL. Ministério do Trabalho. Secretaria de Políticas de Emprego e Salário. Classificação brasileira de ocupações: CBO 94. 2. ed. Brasília: SPES, c1995. 905 p.

BRASIL. Ministério do Trabalho e Emprego. Classificação brasileira de ocupações: CBO 2002. Brasília: MTE, 2003. 1 CD-ROM. Versão 1.1.

BUREAU OF LABOR STATISTICS. Librarians. Washington, DC, 2004. 3 p. Disponível em <http://stats.bls.gov/oco/pdf/ocos068.pdf>. Acesso em: 22 jul. 2004.

CASTELLS, M. Sociedade em rede. 6. ed.rev.ampl. São Paulo: Paz e Terra, 2002. 698 p. (A era da informação: economia, sociedade e cultura, v. 1).

CUNHA, M. V.; CRIVELLARI, H. M. T. O mundo do trabalho na sociedade do conhecimento e os paradoxos das profissões da informação. In: VALENTIM, M. L. P. (Org.). Atuação profissional na área de informação. São Paulo: Polis, 2004. p. 39-54.

FLIGENSPAN, F. B. Ganhos e perdas no mercado de trabalho no real: uma revisão por posição na ocupação. In: ENCONTRO NACIONAL DE ESTUDOS DO TRABALHO, 8., 2003, São Paulo. Anais... São Paulo: USP, 2003. 1 CDROM.

INSTITUTO BRASILEIRO DE GEOGRAFIA E ESTATÍSTICA - IBGE. Microdados do Censo Demográfico 2000: questionário da amostra. 2. ed. Rio de Janeiro: IBGE, 2003. 16 CD-ROM.

INSTITUTO BRASILEIRO DE GEOGRAFIA E ESTATÍSTICA - IBGE. População total: Brasil em 2000. Disponível em $<$ www.ibge.gov.br/home/estatistica/populacao/censo2000/tabelabrasil111 .shtm >. Acesso em: 9 set. 2004.

JANNUZZI, P. M. Indicadores sociais no Brasil: conceitos, fontes de dados e aplicações para - formulação e avaliação de políticas públicas: elaboração de estudos socioeconômicos. Campinas: Alínea, 2001. 141 p.

JANNUZZI, P. M. As ocupações brasileiras segundo a CBO 2002: caracterização empírica com base no Censo 2000. Campinas, 2003. 24 p. Mimeo.

JANNUZZI, P. M.; MATTOS, F. A. M. Duas décadas de conjuntura econômica, de (des)emprego industrial e de inserção dos profissionais da 
informação no mercado de trabalho. Transinformação ${ }_{\perp}$ Campinas, v. 13, n. 2, p. 111-129, jul./dez. 2001.

LOUREIRO, M. F. O bibliotecário como profissional da informação: análise da inserção no mercado de trabalho brasileiro segundo o Censo Demográfico de 2000. 2004. 131 f. Dissertação (Mestrado em Ciência da Informação) - Programa de Mestrado em Ciência da Informação, Pontifícia Universidade Católica de Campinas, Campinas, 2004.

MIRANDA, A. Sociedade da informação: globalização, identidade cultural e conteúdos. Ciência da Informação, Brasília, v. 29, n. 2, p. 78-88, maio/ago. 2000.

SCHWARTZ, G. As profissões do futuro. São Paulo: PubliFolha, 2000. 106 p. (Folha explica, 11).

SMIT, J. W. O profissional da informação e sua relação com as áreas de Biblioteconomia/Documentação, Arquivologia e Museologia. In: VALENTIM, M. L. P. (Org.). O profissional da informação: formação, perfil e atuação profissional. São Paulo: Polis, 2000. p. 119-134.

STATISTICAL Package for the Social Sciences for Windows. Version 11.0 release. [Chicago], 2001.

TAKAHASHI, T. (Org.). Sociedade da informação no Brasil: Livro Verde. Brasília: Ministério da Ciência e Tecnologia, 2000. 195 p. 